\title{
Ultra-performance liquid chromatography- quadrupoleltime-of- flight mass spectrometry with multivariate statistical analysis for exploring potential chemical markers to distinguish between raw and processed Rheum palmatum
}

\author{
Zenghui Wang ${ }^{1}$, Dongmei Wang ${ }^{1}$, Sihao Zheng ${ }^{1}$, Labin $\mathrm{Wu}^{1}$, Linfang Huang ${ }^{1 *}$ and Shilin Chen ${ }^{2}$
}

\begin{abstract}
Background: The long term use of Rheum palmatum for the treatment of diseases associated with chronic hepatitis and renal failure can lead to liver and kidney damage. To reduce the toxicity of $R$. palmatum and alleviate any symptoms of decanta and celialgia, the raw material has been subjected to a specific process prior to its use for hundreds of years. Despite its extensive use in medicine, very little is currently known about the nature of the components present in this material in terms of their efficacy and overall toxicity, and the effect that processing has on the levels of these components in the processed material. The aim of this investigation was to explore potential differences in the chemical markers between batches of raw and processed R. palmatum and to develop a deeper understanding of the underlying mechanisms responsible for the enhanced efficacy and reduced toxicity of the processed material.
\end{abstract}

Methods: Raw and processed R. palmatum samples were analyzed by ultra-performance liquid chromatographyquadrupole time-of-flight mass spectrometry (UPLC/Q-TOF-MS) coupled with multivariate statistical analysis using principal component analysis (PCA) and orthogonal partial least square discriminant analysis (OPLS-DA). Results: The emodin-8-O-glucoside, emodin-O-glucoside, catechin-glucopyranoside, gallic acid-3-O-glucoside, torachrysone, and chrysophanol dimethyl ether were rapidly explored as representative markers to distinguish for the first time between the raw and processed R. palmatum material. Among the potential chemical markers, Emodin-8-O-glucoside and gallic acid-3-O-glucoside were determined to be the best markers for the raw and processed R. palmatum.

Conclusion: UPLC/Q-TOF-MS with multivariate statistical analysis represents an efficient method for exploring the chemical markers in the raw and processed R. palmatum material, as well as investigating the mechanisms associated with the processing, quality control, and safe application of R. palmatum.

Keywords: Ultra-performance liquid chromatography-quadrupoleltime-of-flight mass spectromet- ry, Multivariate statistical analysis, Rheum palmatum, Herb processing, Chemical markers

\footnotetext{
* Correspondence: Ifhuang@implad.ac.cn

1 Institute of Medicinal Medicinal plant Development, Chinese Academy of Medical Sciences \& Peking Union Medical College, Beijing 100193, China

Full list of author information is available at the end of the article
} 


\section{Background}

Processing is an important part of traditional Chinese medicine (TCM), and most of the processes involved in TCM were developed almost 5,000 years ago, along with a number of processing technology theories and methods, such as frying with sand or oil, sautéing with rice wine or wheat bran, steaming with water or rice wine, and braising with rice wine or licorice liquids [1]. According to the theories of TCM, the main purposes of herb processing are to increase potency, reduce toxicity, and alter the effectiveness of the raw materials. The major mechanisms underlying herb processing are predominantly related to changes in the chemical composition and/or activity of the components in herbs [2].

$R$. palmatum, which is known as Da-huang $(\mathrm{DH})$ in Chinese, is officially listed in the Chinese Pharmacopoeia [3] and is widely used as a TCM for alleviating the symptoms of fever, moistening aridity, purging fire, and detoxifying toxicosis [4]. R. palmatum contains a variety of different components, including anthraquinones, dianthrones, stilbenes, anthocyanins, flavonoids, polyphenols, organic acids, and chromones [5]. Among these materials, several anthraquinone derivatives, including emodin, chrysophanol, rhein, aloe-emodin, and physcion, as well as their corresponding glucosides, have been identified as important bioactive components, and reported to exhibit a variety of pharmacological effects, such as purgative [6], anti-inflammatory [7], anticancer [8], nephric protection [9], hepatic protection [10], antimicrobial and hemostasis activities [11,12]. Several reports have appeared in the literature, however, suggesting that the rhubarb components of $R$. palmatum have an adverse impact on liver and kidney function, as well as causing gastrointestinal reactions [13-15], and some of the anthraquinone and tannin compounds present in $R$. palmatum have been reported to be toxic [16]. $R$. palmatum has been subjected to the standard processing technologies used in TCM reduce the toxicity of the raw material, as well as alleviating any symptoms of decanta and celialgia, and the resulting material has been used in clinical practice for hundreds of years $R$. palmatum wine, prepared $R$. palmatum, and charred $R$. palmatum have been well documented in the Chinese Pharmacopoeia as therapeutic materials [4], whereas the use of vinegar $R$. palmatum has been recorded in the standardized processing of traditional Chinese medicine (version 1988) [17]. Potential chemical markers and mechanisms of increased effect and decreased toxicity of $R$. palmatum are yet to be identified and understood. In this study, we have proposed an experimental scheme of screening the markers and identifying raw and processed $R$. palmatum (Figure 1).

Ultra-performance liquid chromatography-quadrupole time-of-flight mass spectrometry (UPLC-QTOF-MS) is a newly developed technique that provides rapid and efficient access to detailed information pertaining to the nature of specific components within complex multicomponent mixtures. UPLC-QTOF-MS has been widely used in various fields for the analysis of a broad range of different materials, and has been used to particularly good effect for metabolite analysis and the identification of the complex compounds found in TCMs [18]. We previously reported the use of UPLC-QTOF-MS in conjunction with multivariate statistical analysis to discriminate between raw and processed samples of Coptis chinensis and Eriobotrya japonica [19-21]. This technique has several significant

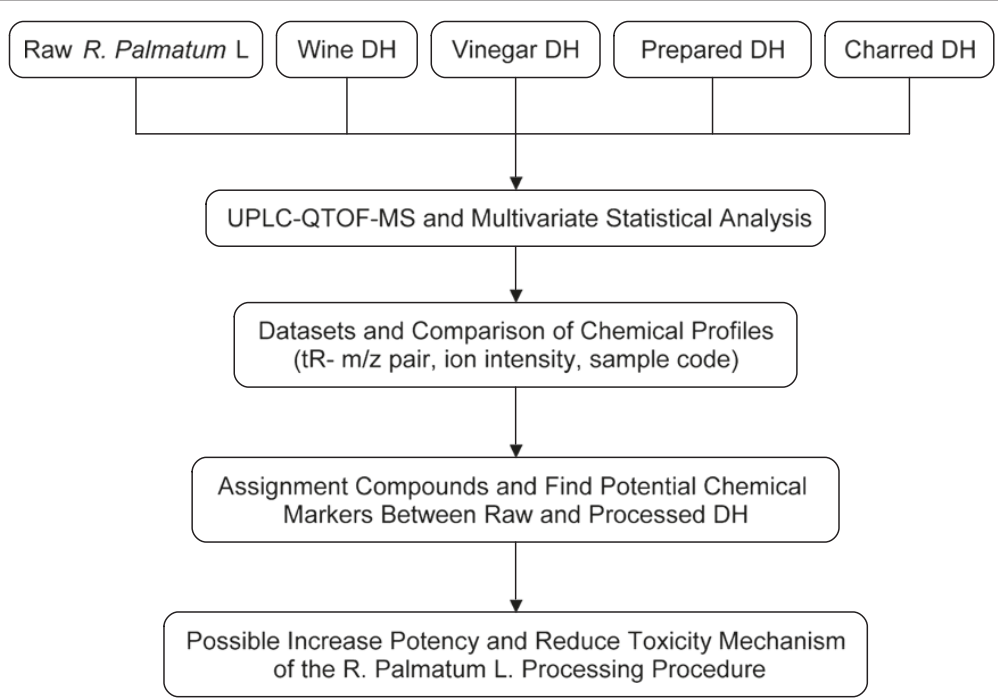

Figure 1 Strategy proposed for rapidly exploring potential chemical markers for discrimination of raw and processed R. palmatum by UPLC-QTOF-MS coupled with multivariate statistical analysis. 
advantages over traditional phytochemical methods for identifying chemical markers, in that it avoids the requirement for time-consuming extraction, isolation, purification, and identification processes. Herein, we describe the development of an effective UPLC-QTOF-MS method that is capable of distinguishing between raw and processed $R$. palmatum (i.e., raw wine $R$. palmatum, vinegar $R$. palmatum, prepared $R$. palmatum, and charred $R$. palmatum) using principal component analysis (PCA) and orthogonal partial least square discriminant analysis (OPLS-DA). To the best of our knowledge, this method represents the first reported account of an analytical method capable of differentiating between raw and processed $R$. palmatum. Several chemical markers were screened and tentatively identified in batches of the raw and processed materials between each processed sample. The results of this study have provided a deeper understanding of the underlying mechanisms responsible for the increased efficacy and decreased toxicity of the processed material. This approach therefore represents a useful tool for distinguishing between raw and processed $R$. palmatum.

\section{Methods}

\section{Chemicals, solvents, and samples}

UPLC-grade acetonitrile, methanol, and formic acid were purchased from Fisher Scientific Co. (Fair Lawn, MA, USA). All of the aqueous solutions used in the current study were prepared using ultrapure water produced by a Milli-Q system (18.2 M $\Omega$, Millipore, Billerica, MA, USA).

$R$. palmatum was collected from Gansu Minxian (Gansu, China) on the November 20, 2012. The botanical materials were identified by Professor Lin Yulin, and voucher specimens were deposited at the Institute of Medicinal Plant Development, Chinese Academy of Medical Sciences, Beijing, China. The detail of the samples' vouchers lists as sdh1-3 of Raw DH (R), dht1-3 of Charred DH (C), shudh1-3 of Prepared DH (P), jdh1-3 of Wine DH (W), cdh1-3 of Vinegar DH (V).

\section{Liquid chromatography}

Two microliter samples were analyzed on a $2.1 \times$ 100 mm ACQUITY ${ }^{\mathrm{m}} 1.7 \mu \mathrm{m}$ BEH C18 column (Waters, Milford, MA, USA), which was maintained at $40^{\circ} \mathrm{C}$ using an Waters ACQUITY ${ }^{\mathrm{sm}}$ UPLC system. The mobile phases consisted of $(\mathrm{A})$ water containing $0.1 \%(\mathrm{w} / \mathrm{w})$ formic acid and (B) methanol. The UPLC elution conditions were optimized as follows: linear gradient from 5 to $15 \%$ B (0 to $2.0 \mathrm{~min}$ ), 15 to $20 \% \mathrm{~B}$ (2.0 to $3.0 \mathrm{~min}$ ), and 20 to $25 \% \mathrm{~B}$ (3 to $4 \mathrm{~min}$ ), where it was held for $1 \mathrm{~min}$ before being increased from 25 to $30 \%$ B (5 to $6 \mathrm{~min}$ ), 30 to $40 \%$ B (6 to $7 \mathrm{~min}$ ), 40 to $55 \% \mathrm{~B}$ (7 to $8 \mathrm{~min}$ ), 55 to $65 \%$ B (8 to $9 \mathrm{~min}$ ), 65 to $85 \%$ B (9 to $10 \mathrm{~min}$ ), 85 to $95 \%$ B (10 to $11 \mathrm{~min}$ ), and 95 to $5 \% \mathrm{~B}$ (11 to $12 \mathrm{~min}$ ), where it was then held for
$3 \mathrm{~min}$. The flow rate was set at $0.35 \mathrm{~mL} / \mathrm{min}$, and the column and autosampler were maintained at 40 and $5^{\circ} \mathrm{C}$, respectively. Each wash cycle consisted of $200 \mu \mathrm{l}$ of the strong solvent $(80 \% \mathrm{ACN}$ in water $-\mathrm{v} / \mathrm{v})$ and $600 \mu \mathrm{L}$ of the weak solvent $(30 \% \mathrm{ACN}$ in water $-\mathrm{v} / \mathrm{v})$. The scan range for PDA detector system was set at 190 to $400 \mathrm{~nm}$. All of the experiments were performed in triplicate.

\section{Mass spectrometry}

MS analysis was performed on a Q-TOF premier mass spectrometer (Waters Micromass Technologies, Manchester, UK), which was operated in the negative ion mode using electrospray ionization. The capillary and cone voltages were set to 3000 and $35 \mathrm{~V}$, respectively. The nebulization gas was maintained at a flow rate of $800 \mathrm{~L} / \mathrm{h}$ and a temperature of $450^{\circ} \mathrm{C}$. The cone gas was maintained at a flow rate of $50 \mathrm{~L} / \mathrm{h}$, and the source temperature was set to $120^{\circ} \mathrm{C}$. MS data were collected for $m / z$ values in the range of 50 to $1,200 \mathrm{Da}$ with a scan time of $0.1 \mathrm{~s}$ and an inter-scan delay of $0.01 \mathrm{~s}$ over an analysis time of a $15 \mathrm{~min}$. The $[\mathrm{M}-\mathrm{H}]^{-}$ ion of leucine-enkephalin was seen at $\mathrm{m} / z$ 556.2771, with a concentration of $0.5 \mathrm{ng} / \mu \mathrm{L}$ in the negative ion mode. Argon was employed as the collision gas at a pressure of $7.066 \times 10^{-3} \mathrm{~Pa}$. All of the MS data were collected using the LockSpray system to ensure mass accuracy and reproducibility.

\section{Sample preparation}

$R$. palmatum samples were processed according to the methods described in the 2010 edition of the Chinese Pharmacopoeia. Raw R. palmatum (R) were cut into 2to 4-mm-thick slices or pieces and then dried. Wine $R$. palmatum (W) was prepared with rice wine $(20 \% \mathrm{w} / \mathrm{w})$. Vinegar $R$. palmatum (V) was prepared with vinegar (20\% w/w). Prepared $R$. palmatum (P) was prepared with rice wine $(20 \% \mathrm{w} / \mathrm{w})$ and then steamed until it was black in appearance on both its inside and outside. Charred $R$. palmatum $(\mathrm{C})$ was prepared by stir frying $R$. palmatum until it was black/brown in color on the outside and burnt-brown or black/brown in color on the inside. All of the samples were milled into powders, and individual portion of the powdered samples $(0.150 \mathrm{~g})$ were dissolved in methanol. The resulting samples were then extracted for $30 \mathrm{~min}$ using an ultrasonic cleaner in a water bath $\left(45^{\circ} \mathrm{C}\right)$. The extracts were centrifuged at $12,000 \mathrm{rpm}$ for $20 \mathrm{~min}$, and the supernatant was injected directly into the UPLC-Q/TOF system for analysis.

Establishment of an in-house library and peak assignment Data pertaining to the different components of $R$. palmatum were collected from various different databases, including PubMed for the U.S. National Library of Medicine and the National Institute of Health, 
SciFinder Scholar for the American Chemical Society, and the Chinese National Knowledge Infrastructure of Tsinghua University. The collected data were summarized in a Microsoft Office Excel table to establish an in-house library, which included the name, molecular formula, UV maximum wavelength, chemical structure, and reference of each known compound. The "Find" function in Microsoft Office Excel was used to match the empirical molecular formula with that of published compounds within the library. The empirical molecular formula was deduced from and shortlisted by comparing the accurately measured mass value to the exact mass value of putative deprotonated molecular ions $[\mathrm{M}-\mathrm{H}]^{-}$at a mass accuracy of less than $5 \mathrm{ppm}$.

\section{Multivariate data processing}

The UPLC-MS data of all determined samples were analyzed using the MarkerLynx software (Waters) to identify potential discriminatory chemical markers and allow for the raw and processed $\mathrm{DH}$ to be subjected to some measure of quality control. For data collection, the method parameters were set as follows: retention time in the range of 0 to $15 \mathrm{~min}$, mass in the range of 50 to $1200 \mathrm{Da}$, and noise elimination level set at 5. For data analysis, a list composed of the identities of the detected peaks was generated using retention time $\left(t_{R}\right)$ - mass data $(\mathrm{m} / z)$ pairs as the identifier for each peak. An arbitrary ID was assigned to each of these $t_{R}-m / z$ pairs based on their order of elution from the UPLC system. The ion intensity for each detected peak was normalized against the sum of the peak intensities within that sample. Ion identification was based on the $t_{\mathrm{R}}$ and $m / z$ values. Pareto scaling method was used to generate the PCA plot. The resulting three-dimensional data comprising the peak number $\left(t_{R}-m / z\right.$ pair $)$, sample name, and ion intensity were analyzed by PCA and OPLS-DA.

\section{Results and discussion}

\section{Chromatographic conditions of UPLC}

Several different mobile phase systems were evaluated in the current study, including the use of an organic phase (i.e., acetonitrile and methanol) with a variety of different aqueous phases (i.e., water, water containing formic acid, water containing triethylamine, as well as water containing formic acid and ammonium). The results of an extensive period of evaluation revealed that a mixture of acetonitrile and water (containing $0.1 \%$ formic acid) was the most suitable mobile phase. The gradient elution profile was optimized with respect to the separation of the major peaks and, under the optimized chromatographic conditions, the major components in $R$. palmatum could be well separated and detected within $15 \mathrm{~min}$.

\section{UPLC-QTOF-MS chemical analysis}

18 compounds were tentatively identified based on their fragment ions (Figure 2) as well as a comparison with data from the literature [22-25]. All of these compounds have been previously reported to be present in $R$. palmatum and are listed in Table 1.

\section{Confirmation of TCM processing theories with raw and processed DH}

The results of the PCA of the raw and processed $R$. palmatum are shown in Figure 3. These results show that the raw $R$. palmatum, wine $R$. palmatum, vinegar $R$. palmatum, prepared $R$. palmatum, and charred $R$. palmatum samples were divided into five main clusters in the PCA score plot. The division of these data into clusters effectively indicated that use of different processing methods could significantly alter the composition of compounds within the different materials, and this separation could therefore be representative of their multiple pharmacological effects. According to the PCA, charred R. palmatum (C) clustered in the upper right region, whereas prepared $R$. palmatum (P) clustered into the bottom right region, In contrast, wine $R$. palmatum (W) and vinegar $R$. palmatum (V) clustered into the bottom left region of the PCA. The prepared $R$. palmatum (P) was clustered far from the middle region, which indicated that remarkable chemical changes had occurred during the processing of this material. The wine $R$. palmatum (W) and vinegar $R$. palmatum (V) clusters were close to each other, which indicated that similar chemical changes had occurred during their processing. The results of this experiment therefore clearly demonstrated the importance of the processing method to the chemical composition of the finished material.

\section{Multivariate statistical analysis and exploring chemical markers}

Extensive statistical analyses were performed to generate an S-plot, which could be used to identify potential chemical markers for distinguishing between raw and processed $R$. palmatum (Figures 4A and 5, and Table 2). In Figure 4A, the first three ions (i.e., a, b, and c) in the bottom left corner of the " $\mathrm{S}$ " are the ions from the raw $R$. palmatum sample that contributed the greatest difference observed in the data between the raw and processed $R$. palmatum. Ions $a, b$, and c could therefore be used as potential chemical markers to distinguish between samples of raw and processed $R$. palmatum. Ion a was identified as the most characteristic of these three chemical markers in raw $R$. palmatum. Similarly, ions $d$, e, and $f$ were identified as the most characteristic ions of processed $R$. palmatum, and represented the biggest difference between the raw and processed $R$. palmatum. The ion 


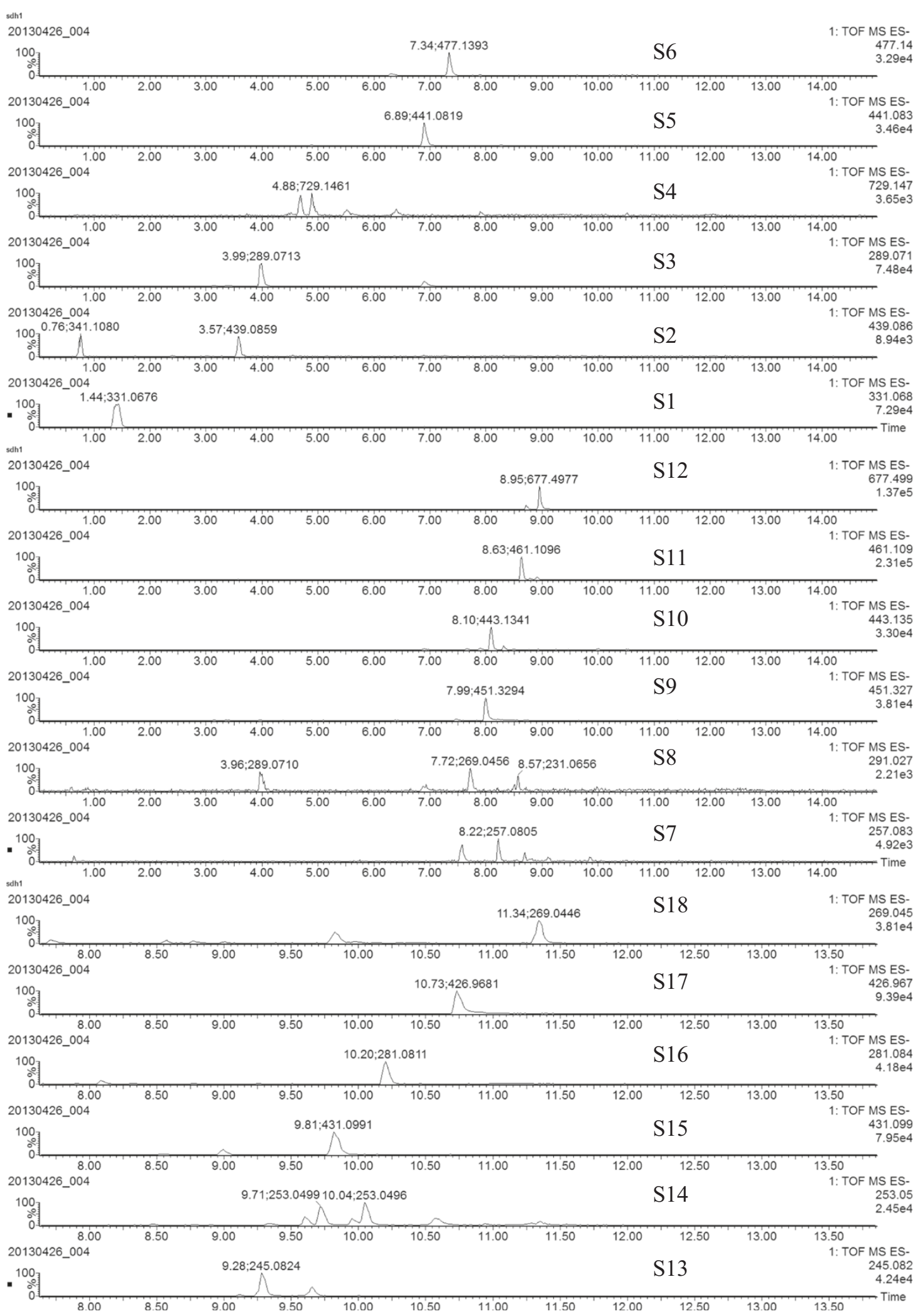

Figure $\mathbf{2}$ Extracted ion chromatograms (EIC) of $\mathbf{1 8}$ components for $\boldsymbol{R}$. Palmatum. The peaks labeling coincide with Table 1. 
Table 1 Tentative compounds in R. Palmatum by UPLC-QTOF/MS in negative ion

\begin{tabular}{|c|c|c|c|c|c|c|c|}
\hline Peak no. & $t_{R}(\min )$ & $\mathrm{m} / \mathrm{z}$ experimental & $\mathrm{m} / \mathrm{z}$ calculated & Tentative compounds & $\begin{array}{l}\text { Molecular } \\
\text { formula }\end{array}$ & $\begin{array}{l}\text { Mass error } \\
(\mathrm{ppm})\end{array}$ & Reference \\
\hline S1 & 1.43 & 331.0667 & 331.0667 & Gallic acid-3-O-glucoside & $\mathrm{C} 13 \mathrm{H} 15 \mathrm{O} 10$ & 0 & [22] \\
\hline S2 & 3.57 & 439.0883 & 439.0883 & Aloe-emodin-glucoside derivate & $\mathrm{C} 21 \mathrm{H} 19 \mathrm{O} 10$ & -1.3 & [22] \\
\hline S3 & 3.96 & 289.0707 & 289.0712 & Catechin & $\mathrm{C} 15 \mathrm{H} 13 \mathrm{O} 6$ & -1.7 & [22] \\
\hline S4 & 4.88 & 729.1470 & 729.1456 & Catechin dimer derivate & $\mathrm{C} 40 \mathrm{H} 69 \mathrm{O} 8$ & 1.9 & [22] \\
\hline S5 & 6.86 & 441.0825 & 441.0822 & Epicatechin-3-O-gallate & $\mathrm{C} 22 \mathrm{H} 17 \mathrm{O} 10$ & 0.7 & [22] \\
\hline S6 & 7.33 & 477.1397 & 477.1397 & Cinnamyl-galloyl-glucoside derivative & $\mathrm{C} 23 \mathrm{H} 25 \mathrm{O} 11$ & 0 & [23] \\
\hline S7 & 7.50 & 257.0827 & 257.0814 & Emodin-O-glucoside & $\mathrm{C} 15 \mathrm{H} 13 \mathrm{O} 4$ & 5.1 & [23] \\
\hline S8 & 7.71 & 269.0450 & 269.0450 & Aloe-emodin & $\mathrm{C} 15 \mathrm{H} 10 \mathrm{O} 5$ & 0 & {$[24,25]$} \\
\hline S9 & 7.99 & 451.3296 & 451.3271 & Catechin-glucopyranoside & $\mathrm{C} 21 \mathrm{H} 24 \mathrm{O} 11$ & 5.5 & [22] \\
\hline S10 & 8.08 & 443.1345 & 443.1345 & Catechin-glucopyranoside derivative & $\mathrm{C} 23 \mathrm{H} 23 \mathrm{O} 9$ & -1.7 & [23] \\
\hline S11 & 8.62 & 461.1085 & 461.1084 & Cinnamyl-galloyl-glucoside derivative & $\mathrm{C} 23 \mathrm{H} 25 \mathrm{O} 11$ & 0.2 & [23] \\
\hline $\mathrm{S} 12$ & 8.95 & 677.4994 & 677.4993 & Catechin dimer derivate & $\mathrm{C} 40 \mathrm{H} 69 \mathrm{O} 8$ & 0.3 & [22] \\
\hline S13 & 9.28 & 245.0824 & 245.0814 & Torachrysone & $\mathrm{C} 14 \mathrm{H} 14 \mathrm{O} 4$ & 0 & [23] \\
\hline S14 & 9.71 & 253.0499 & 253.0501 & Chrysophanol & $\mathrm{C} 15 \mathrm{H} 9 \mathrm{O} 4$ & -0.8 & {$[24,25]$} \\
\hline S15 & 9.81 & 431.0988 & 431.0978 & Emodin-8-O-glucoside & $\mathrm{C} 21 \mathrm{H} 19010$ & 2.3 & [23] \\
\hline S16 & 10.20 & 281.0814 & 281.0811 & Chrysophanol dimethyl ether & $\mathrm{C} 17 \mathrm{H} 14 \mathrm{O} 4$ & -1.1 & [25] \\
\hline S17 & 10.73 & 426.9665 & 426.9691 & Rhein-1-O-(O-acetyl)-glucoside & $\mathrm{C} 4 \mathrm{H} 11 \mathrm{O} 23$ & -6.1 & {$[23]$} \\
\hline S18 & 11.34 & 269.0446 & 269.0450 & Emodin & $\mathrm{C} 15 \mathrm{H} 10 \mathrm{O} 5$ & -1.5 & {$[24,25]$} \\
\hline
\end{tabular}

intensity trends of these ions in the analyzed samples are shown in Figure 4B. Ions a $\left(t_{R} 9.81 \mathrm{~min}, \mathrm{~m} / z\right.$ 331.0667, Emodin-8-O-glucoside), b ( $t_{\mathrm{R}} 7.50 \mathrm{~min}, \mathrm{~m} / \mathrm{z}$ 257.0827, emodin-O-glucoside), and $\mathrm{c}\left(\mathrm{t}_{\mathrm{R}} 7.99 \mathrm{~min}\right.$, $\mathrm{m} / z$ 451.3296, catechin-glucopyranoside) were detected with higher intensities in the raw samples and lower intensities in the other processed samples. However, these ions were not detected in the prepared $R$. palmatum sample. Ions $\mathrm{d}\left(\mathrm{t}_{\mathrm{R}} 1.43 \mathrm{~min}, \mathrm{~m} / z\right.$ 331.0667, Gallic acid-3-O-glucoside), e ( $t_{R} 9.28 \mathrm{~min}, \mathrm{~m} / z$ 245.0824, torachrysone), and $\mathrm{f}\left(\mathrm{t}_{\mathrm{R}} 10.20 \mathrm{~min}, \mathrm{~m} / \mathrm{z}\right.$ Chrysophanol dimethyl ether) were detected with lower intensities in the

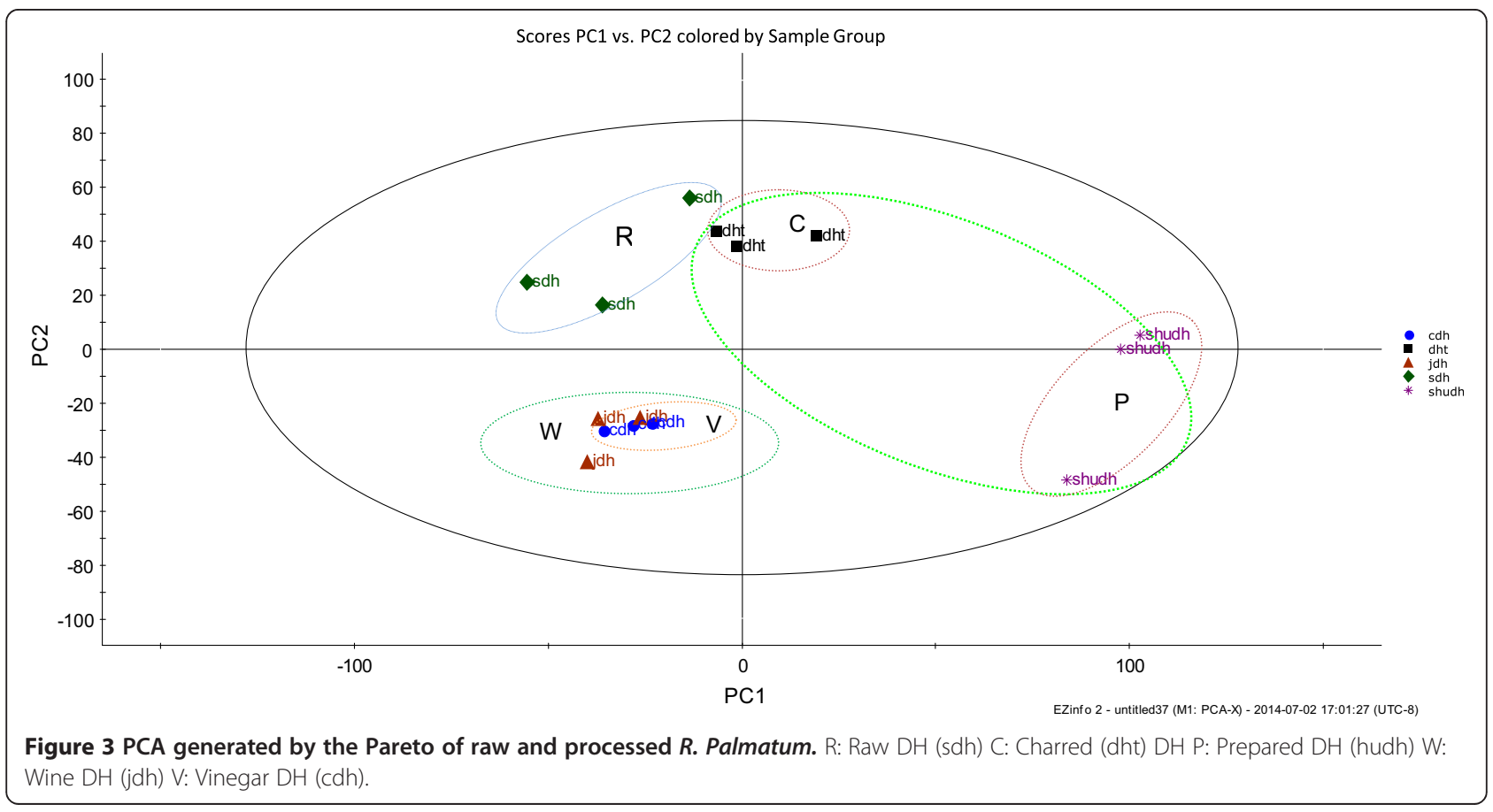




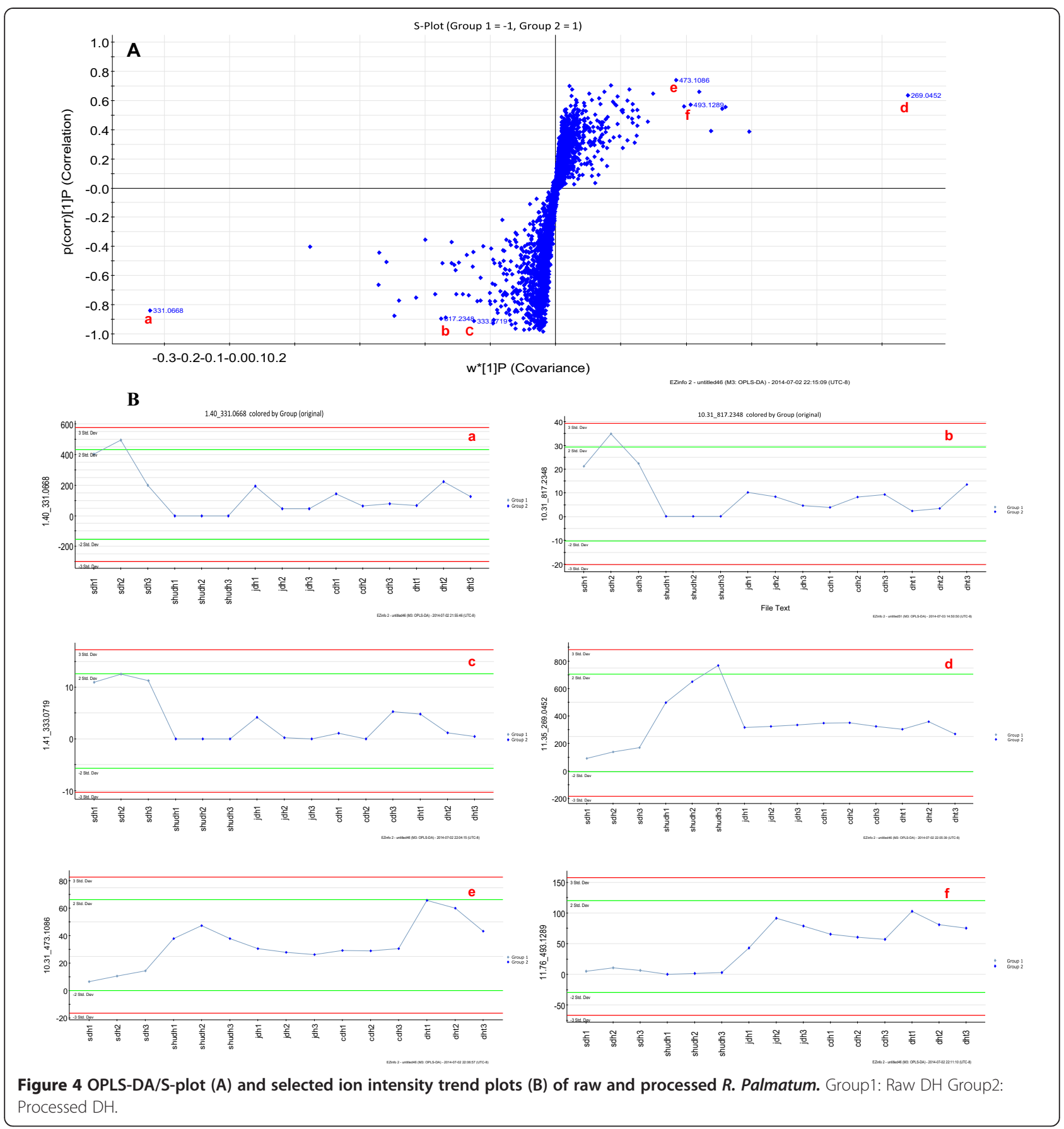

raw $R$. palmatum sample and higher intensities in the processed samples. Ions $\mathrm{d}$, e, and $\mathrm{f}$ could be regarded as potential chemical markers for discriminating between processed and raw $R$. palmatum. Ion $\mathrm{d}$ could be used as the most characteristic chemical marker for the identification of processed $R$. palmatum.

UPLC-QTOF-MS could be used to distinguish raw $R$. palmatum from the different processed $R$. palmatum sampled in conjunction with OPLS-DA (S-plot): Figure 5A raw $R$. palmatum vs. wine $R$. palmatum, Figure 5B raw $R$. palmatum vs. vinegar $R$. palmatum, Figure $5 \mathrm{C}$ raw $R$. palmatum vs. prepared $R$. palmatum, and Figure 5D raw $R$. palmatum vs. charred $R$. palmatum. The circled points were regarded as potential characteristic markers that could be used to distinguish raw $R$. palmatum from the different samples of processed $R$. palmatum (Figure 5, Table 2). Ions a (cinnamyl-galloyl-glucoside derivative) and $g\left(t_{R}, 8.62 \mathrm{~min}, \mathrm{~m} / z\right.$ 461.1085, cinnamyl- 

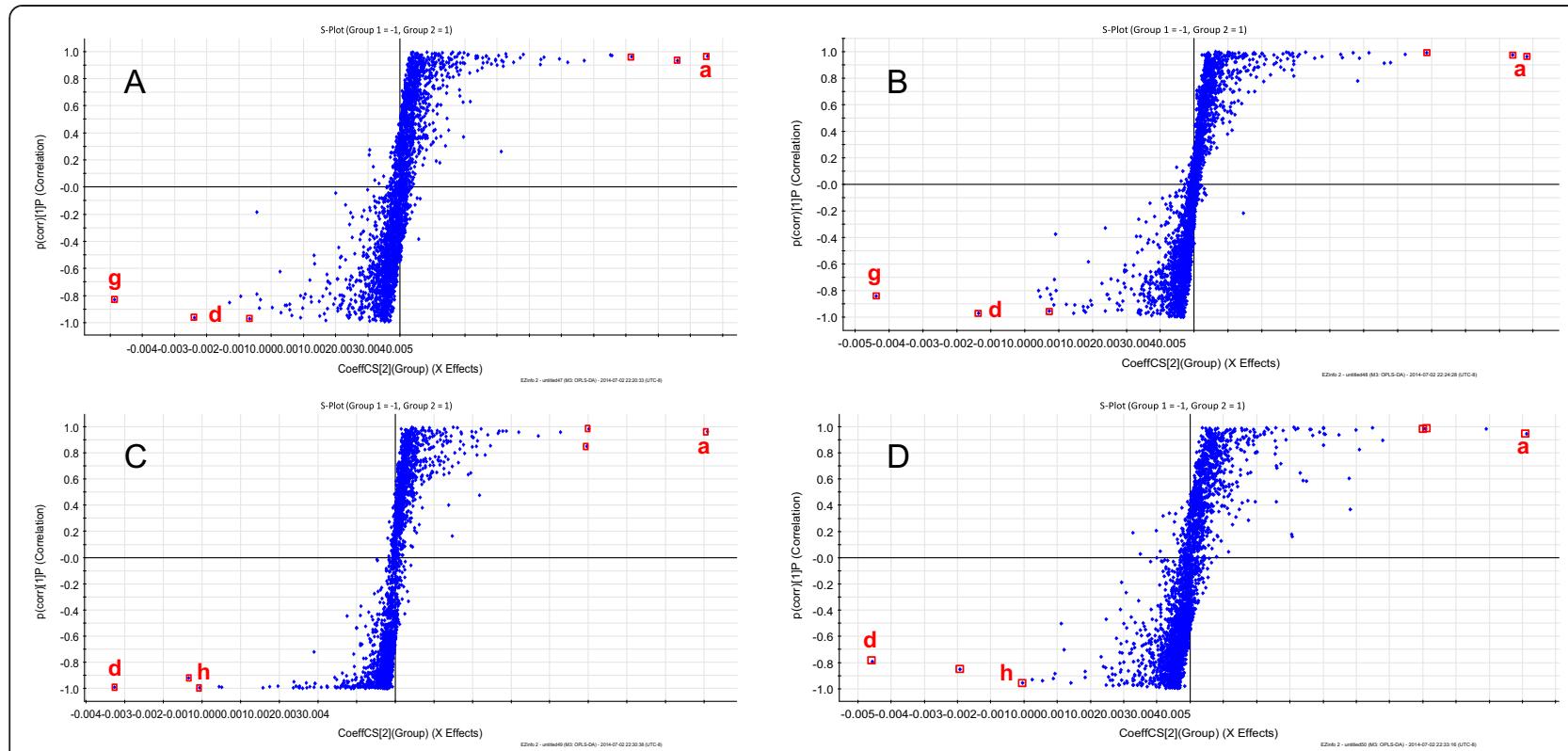

Figure 5 OPLS-DA(S-plot) of Raw and Processed R. Palmatum Sample: A Raw DH vs. Wine DH; B Raw DH vs. Vinegar DH; C Raw DH vs. Prepared DH; D Raw DH vs. Charred DH.

galloyl-glucoside derivative) were the identified as the most characteristic chemical markers for distinguishing between raw $R$. palmatum and wine $R$. palmatum (Figure 5A), as well as distinguishing between raw $R$. palmatum and vinegar R. palmatum (Figure $5 \mathrm{~B}$ ). Ions a (Emodin-8-O-glucoside) and d (Gallic acid-3-Oglucoside) were determined to be the most characteristic chemical markers for distinguishing between raw $R$. palmatum and prepared R. palmatum (Figure 5C), as well differentiating between raw $R$. palmatum and charred R. palmatum (Figure 5D). Ions a and d could therefore be used as chemical markers to discriminate between raw and processed $R$. palmatum (including prepared $R$. palmatum and charred $R$. palmatum), whereas ions a and $g$ could be used as the best characteristic markers to distinguish between raw $R$. palmatum and vinegar $R$. palmatum, as well as raw $R$. palmatum and wine $R$. palmatum.

\section{Preliminary study on processing mechanism}

Anthraquinone glycosides make a significant contribution to the hepatic and renal toxicity of raw $R$. palmatum. The Emodin-8-O-glucoside found in $R$. palmatum (ion a) has been reported to be reported to be exhibit the highest levels of hepato- and nephrotoxicity of the anthraquinone glycoside found in $R$. palmatum, whereas chrysophanol (ion h) was reported to be the least toxic of these compounds [26]. The toxicities of the $R$. palmatum materials gradually decreased in the following order: raw $R$. palmatum $>$ wine $R$. palmatum $\approx$

Table 2 Marker $t_{R}-m / z$ ion pairs of raw and processed $R$

\begin{tabular}{|c|c|c|c|c|c|c|c|c|c|}
\hline \multicolumn{2}{|c|}{$\begin{array}{c}\text { Raw DH/Processed DH } \\
t_{R^{-}} m / z\end{array}$} & \multicolumn{2}{|c|}{$\begin{array}{c}\text { Raw } D H / \text { vinegar DH } \\
t_{R^{-}} \mathbf{m} / \mathbf{z}\end{array}$} & \multicolumn{2}{|c|}{$\begin{array}{c}\text { Raw DH/ wine DH } \\
t_{R^{-}} m / z\end{array}$} & \multicolumn{2}{|c|}{$\begin{array}{c}\text { RawDH/ prepared DH } \\
t_{R^{-}}-m / z\end{array}$} & \multicolumn{2}{|c|}{$\begin{array}{c}\text { Raw DH/ charred DH } \\
t_{R}-m / z\end{array}$} \\
\hline \multirow[t]{3}{*}{ Raw DH } & $9.81-431.0988^{(a)}$ & Raw DH & $9.81-431.0988^{(a)}$ & Raw DH & $9.81-431.0988^{(a)}$ & Raw DH & $9.81-431.0988^{(a)}$ & Raw DH & $9.81-431.0988^{(a)}$ \\
\hline & 7.99-451.3296 & & $7.99-451.3296$ & & $7.99-451.3296$ & & $7.99-4$ & & 3296 \\
\hline & $3.57-431.0861$ & & $3.57-431.0861$ & & $3.57-431.0861$ & & $3.57-431.0861$ & & $3.57-431.0861$ \\
\hline \multirow{3}{*}{$\begin{array}{l}\text { Processed } \\
\mathrm{DH}\end{array}$} & $1.43-331.0667^{(d)}$ & \multirow{3}{*}{$\begin{array}{l}\text { Vinegar } \\
\mathrm{DH}\end{array}$} & $1.43-331.0667^{(d)}$ & Wine $\mathrm{DH}$ & $1.43-331.0667^{(\mathrm{d})}$ & Prepared DH & $1.43-331.0667^{(d)}$ & Charred DH & $1.43-331.0667^{(d)}$ \\
\hline & $9.71-253.0499$ & & $7.33-477.1396^{(g)}$ & & $7.33-477.1396^{(\mathrm{g})}$ & & $10.20-281.0814$ & & $10.20-281.0841$ \\
\hline & $10.20-281.0814$ & & 8.60-283.0291 & & $8.60-283.0291$ & & $9.71-253.0499^{(h)}$ & & $9.71-253.0499^{(h)}$ \\
\hline
\end{tabular}

Palmatum samples in the S-plot.

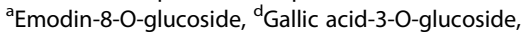

${ }^{9}$ Cinnamyl-galloyl-glucoside derivative, ${ }^{\mathrm{h}}$ Chrysophanol. 
vinegar $R$. palmatum $>$ prepared $R$. palmatum $>$ charred $R$. palmatum (Table 3 ). This result may be related to the conversion of the anthraquinone glycosides in the $R$. palmatum samples into the corresponding free anthraquinones in the processed materials. These results provide a better explanation of the previous results (Tables 2 and 3). The cinnamyl-galloyl-glucoside derivative (ion a) was determined to be the most characteristic chemical marker for the identification of raw $R$. palmatum, whereas chrysophanol (ion h) could be used as a potential chemical marker for the identification of prepared and charred R. palmatum samples.

Raw $R$. palmatum exhibits a significant heat-clearing effect and purgative activity, which is consistent with the properties of bitter cold and sedimentation described in the theory of TCM. The cinnamyl-galloyl-glucoside derivative (ion a) makes a significant contribution to the purgative effects of $R$. palmatum. Consideration of the purgative effects of the different samples revealed the following trend: raw $R$. palmatum $>$ wine $R$. palmatum $\approx$ vinegar $R$. palmatum $>$ prepared $R$. palmatum $>$ charred $R$. palmatum. A similar trend was also observed in the bitter cold properties of raw and processed $R$. palmatum samples (Table 3). Gallic acid-3-O-glucoside (ion d) made the greatest contribution to the convergence effect of $R$. palmatum. Consideration of the convergence effects of the different materials revealed the following trend: charred $R$. palmatum $>$ prepared $R$. palmatum $>$ vinegar $R$. palmatum $\approx$ wine $R$. palmatum $>$ raw $R$. palmatum (Table 3).

Previous studies have indicated that the basic components of raw $R$. palmatum are anthraquinone glycoside compounds, and this information is in agreement with the results of the current study (Tables 2 and 3). Furthermore, the chemical markers of raw and processed $R$. palmatum have been explored in considerable detail in this study. The cinnamyl-galloyl-glucoside derivative was determined to be the most characteristic marker in raw $R$. palmatum, whereas it appeared at a much lower level or even disappeared completely in the prepared and charred $R$. palmatum samples because the anthraquinone glycosides were hydrolyzed to the corresponding anthraquinones during the processing stages, which led to the loss of the purgative activities of these samples and a decrease in their antipyretic effects. Furthermore, the effect of promoting blood circulation to remove blood stasis increased. Gallic acid-3-O-glucoside was identified as the most characteristic marker in the charred and prepared $R$. palmatum samples, and the amount of this material increased significantly in the charred and prepared $R$. palmatum samples compared with the raw material. This result could be attributed to the tannins in the raw material being readily hydrolyzed to form gallic acid-3-O-glucoside by steaming with wine or by carbonization.

\section{Conclusion}

UPLC-QTOF-MS in conjunction with multivariate statistical analysis can be used to screen and identify potential chemical markers that could be used to distinguish raw and processed $R$. palmatum. A variety of different $R$. palmatum samples were processed under the same conditions and six ion pairs were identified as chemical markers that could be used to distinguish the raw materials from that of the processed herbs. Two ions, namely those belonging to the emodin-8-Oglucoside and gallic acid-3-O-glucoside, were determined to be potential chemical markers for processed $R$. palmatum. We have also provided a brief discussion of the underlying mechanisms associated responsible for enhancing the efficacy and reducing the toxicity of $R$. palmatum following the traditional processing procedures. The strategy developed in this study was successfully applied to distinguish between samples of raw from processed $R$. palmatum, and could also be used to investigate the mechanisms responsible for the efficacy enhancing and toxicity reducing effects of crude processing techniques in other materials.

Table 3 Toxicity, property and characteristic components of raw and processed DH

\begin{tabular}{|c|c|c|c|c|c|c|}
\hline Toxic & Raw DH & Wine DH & Vinegar DH & Prepared DH & Charred DH & References \\
\hline Nephrotoxicity & $\sqrt{ }$ & $\downarrow$ & $\downarrow$ & $\downarrow$ & $\downarrow$ & {$[16]$} \\
\hline Hepatotoxicity & $\sqrt{ }$ & $\downarrow$ & $\downarrow$ & $\downarrow$ & $\downarrow$ & {$[16]$} \\
\hline Gastrointestinal reactions & $\sqrt{ }$ & $\downarrow$ & $\downarrow$ & $\downarrow$ & $\downarrow$ & {$[17]$} \\
\hline The property of bitter cold & $\sqrt{ }$ & $\downarrow$ & $\downarrow$ & $\downarrow$ & $\downarrow$ & {$[17]$} \\
\hline \multirow[t]{2}{*}{ Characteristic components } & Aloe-emodin & Cinnamyl-galloyl & Cinnamyl-galloyl & Gallic acid & Gallic acid & {$[16]$} \\
\hline & -glucoside & -glucoside & -glucoside & chrysophanol & chrysophanol & {$[17]$} \\
\hline
\end{tabular}

$\downarrow$ : Reduced toxic effects.

$\checkmark$ : Toxic. 


\section{Competing interests}

The authors declare that they have no competing interests.

\section{Authors' contributions}

ZW, SZ and DW carried out the experiments, participated in the statistical analysis and drafted the manuscript. LH conceived of the study, participated in its design, and revised the manuscript. LW participated in the statistical analysis. All authors read and approved the final version of the manuscript.

\section{Acknowledgment}

The study was supported by grants from the National Natural Science Foundation of China (No. 81274013), Key National Natural Science Foundation of China (81130069), and the Chinese National S\&T Special Project on Major New Drug Innovation (2011ZX09307-002-01). The program for Changjiang Scholars and Innovative Research Team in University of Ministry of Education of China (IRT1150). The funders had no role in study design, data collection and analysis, decision to publish, or preparation of the manuscript.

\section{Author details}

${ }^{1}$ Institute of Medicinal Medicinal plant Development, Chinese Academy of Medical Sciences \& Peking Union Medical College, Beijing 100193, China. ${ }^{2}$ Institute of Chinese Materia Medica, China Academy of Chinese Medical Sciences, Beijing 100193, China.

Received: 28 November 2013 Accepted: 13 August 2014

Published: 16 August 2014

\section{References}

1. Huang ZS: Traditonal Chinese Medicine. Beijing: The People's Medical Publishing House; 2002.

2. Jin SY, Wang Q: Studies on Processing of Chinese Medicinal Yinpian and Its Clinical Application. Beijing: Press of Chemistry Industry; 2004.

3. Cai BC, Gong QF: Processing of Chinese Medicinal Herbs. Beijing: People Health Press; 2009.

4. China Pharmacopoeia Committee: China Pharmacopoeia. Beijing: China Chemical Industry Press; 2010.

5. Kashiwada Y, Nonaka Gl, Nishioka I: Studies on Rhubarb (Rhei Rhizoma).XV. Simultaneous determination of phenolic constituents by high-performance liquid chromatography. Cheml Pharm Bull 1989, 37(4):999-1004.

6. Xiao $P G, H e L Y$, Wang LW: Studies on the relations of chemical constituents and activities among genus Rheum. J Ethnopharmacol 1984, 10:275-293

7. Cuellar MJ, Giner RM, Recio MC, Manez S, Rios JL: Topical anti- inflammatory activity of some Asian medicinal plants used in dermatological disorder. Fitoterapia 2001, 72(3):221-229.

8. Huang Q, Lu G, Shen HM, Chung MC, Ong CN: Anti-cancer properties of anthraquinones from rhubarb. Med Res Rev 2007, 27(5):609-630.

9. Yokozawa T, Suzuki N, Okudal Oura H, Nishioka I: Changes in the uri-nary constituents in rats with chronic renal failure during oral administration of rhubarb extract. Chem Pharm/ Bull 1985, 33(10):4508-4514.

10. Zhao YL, Wang JB, Zhou GD, Shan LM, Xiao XH: Investigations of free anthraquinones from rhubarb against a-naphthylisothiocyan- ate-induced cholestatic liver injury in rats. Basic Clinl Pharmacol 2009, 104(6):463-469.

11. Zhao GP, Dai S, Chen RS: Dictionary of Traditional Chinese Medicine Shanghai: Shanghai science and Technology Press; 2006.

12. World Health Organization: WHO monographs on selected medicinal plants (Vol. 2). World Health Organization; 2002.

13. Wang CF, Wu XD, Chen M, Duan WG, Sun LX, Yan M, Zhang LY: Emodin induces apoptosis through caspase 3-dependent pathway in HK-2 cells. Toxicology 2007, 231(2-3):120-128.

14. Zhang $L Y$, Jiang $Z Z$, Pu CH, Yan M: Six-month oral toxicity study of total anthraquinone in Radix et Rhizoma Rhei in SD rats. Chin J Biochem Pharm 2004, 25(4):206-209.

15. Wang JB, Zhao YL, Xiao XH, Li HF, Zhao HP, Zhang P, Jin C: Assessment of the renal protection and hepatotoxicity of rhubarb extract in rats. $J$ Ethnopharmacol 2009, 124(1):18-25.

16. Wang JB, Ma YG, Zhang $P$, Jin C, Sun YQ, Xiao XH, Zhao YL, Zhuo C-P: Effect of processing on the chemic al contents and hepatic and renal toxicity of rhubarb studied by canonical correlation analysis. Acta Pharm Sin 2009, 44(8):885-890.
17. Guo P, Zhang TJ, Zhu XY, He YZ: Study on toxicity of Radixet Rhizoma Rhei and countermeasure for its attenuation. Chin Tradit Herb Drugs 2009, 40(10):1671-1674.

18. Drug administration in Ministry of Health: Prepared standard of traditional chinese medicine in China. Beijing: People's Medical Publishing House; 1988:627.

19. Churchwella MI, Twaddlea NR, Meekerb CL, Doergea DR: Improving LC-MS sensitivity through increases in chromatographic performance: comparisons of UPLC-ES/MS/MS to HPLC-ES/MS/MS. J Chromatogr B 2005, 825(2):134-143.

20. Jiang $X$, Huang LF, Wu LB, Wang ZH, Chen SL: UPLC-QTOF/MS analysis of Alkaloids in Traditional Processed Coptis chinensis Franch. Evid-Based Complement Altern Med 2012, 2012:ID942384.

21. Wu LB, Jiang X, Huang LF, Chen SL: Processing Technology Investigation of Loquat (Eriobotrya japonica) Leaf by Ultra-Performa- nce Liquid Chromatography-Quadrupole Time-of-Flight Mass Spectrometry Combined with Chemometrics. PLoS One 2013, 8(5):e64178.

22. Jiang $H Q$, Rong $R$, Lu QT: Identification of chemical composition in Rhunarb by high performance Liquid Chromatography with Mass Spectrometry. LiShiZhen Med Materia Med Res 2011, 22(7):1705-1706.

23. Ye M, Han J, Chen HB, Zheng JH, Guo D: Analysis of phenolic compounds in rhubarbs using liquid chromatography coupled with electrospray Ionization mass spectrometry. J Am Soc Mass Spectr 2007, 18(1):82-91.

24. Sun H, Zhu C, Zhang HY, Wang YR, Luo GA, Hu P: Comparative analysis of main constituents of Radix et Rhizoma Rhei and processed Radix et Rhizoma Rhei by HPLC-ESI-TOF-MS. Chin Tradit Patent Med 2009, 31(3):420-424.

25. Ma XH, Shen S, Han FM, Chen Y: The electrospray ionization-mass spectra of Radix et rhizoma rhei anthraquinones. Journal of Hubei University (Natural Science) 2006, 28:404-406.

26. Wiklund S, Johansson E, Sjöström L, Mellerowicz E-J, Edlund U, Shockcor J-P, Gottfries J, Moritz T, Trygg J: Visua lization of GC/TOF-MS-based metabolomics data for identification of biochemically interesting compounds using OPLS class models. Anal Chem 2008, 80(1):115-122.

doi:10.1186/1472-6882-14-302

Cite this article as: Wang et al:: Ultra-performance liquid chromatography-quadrupole time-of- flight mass spectrometry with multivariate statistical analysis for exploring potential chemical markers to distinguish between raw and processed Rheum palmatum. BMC Complementary and Alternative Medicine 2014 14:302.

\section{Submit your next manuscript to BioMed Central and take full advantage of:}

- Convenient online submission

- Thorough peer review

- No space constraints or color figure charges

- Immediate publication on acceptance

- Inclusion in PubMed, CAS, Scopus and Google Scholar

- Research which is freely available for redistribution

Submit your manuscript at www.biomedcentral.com/submit
C BioMed Central 